\title{
Informing Health: a participative approach to health information provision
}

\author{
Audrey Marshall and Flis Henwood
}

\begin{abstract}
This article reports on a research project which took place in Brighton in 2006. It was part of ongoing research into the role that information and communications technologies (ICTs) might play in enabling access to health information. It discusses the relevant policy areas, the approaches used in the research and the key findings. It sought to develop a model for good practice in community engagement around health information, adopting an approach based on participation and knowledge exchange. The discussion focuses on three themes arising from the study: different interpretations of health and health information; the role of libraries in health information provision; the benefits and issues of working in a partnership which includes community participants. The project demonstrated positive aspects of partnership working and community engagement, which can be used as a basis for further development, as well as some of the challenges inherent in such an approach.
\end{abstract}

\section{Introduction}

Informing Health was a small scale pilot project which took place in Brighton between April and December 2006. It was funded by the Community University Partnership Programme (CUPP) ${ }^{1}$ and was conducted by the Social Informatics Research Unit (SIRU) at the University of Brighton. It was part of ongoing research into the role that information and communications technologies (ICTs) might play in enabling access to health information. This article discusses the policy context, the approaches used in the research and the key findings. It focuses on three themes arising from the study: different perspectives on the concepts of health and health information; the role of libraries in health

\footnotetext{
${ }^{1}$ CUPP aims to support partnership working between the University of Brighton and local communities: http://www.brighton.ac.uk/cupp/
}

\section{Authors}

Audrey Marshall is a Senior Research Fellow at the University of Brighton. She teaches library studies and has a particular research interest in health information.

E-mail: a.m.marshall@brighton.ac.uk

Flis Henwood is Professor of Social Informatics at the University of Brighton. She has published widely on e-health issues in academic and practitioner journals. 
information provision; the benefits and issues of working in a partnership which includes community participants.

\section{Policy context}

Since its election in 1997 the UK Labour government has issued a succession of health policies which have increasingly reinforced the importance of information as a pre-requisite for decision-making in health. In 2004, the government published a new public health White Paper, Choosing Health (Department of Health, 2004) which takes as its starting point "informed choice" about health and which emphasises that the key task of government is to provide access to "clear and credible information". It acknowledges the wide range of sources people currently use to get information about health, including public libraries and the internet.

Public libraries have a long history of providing access to health information (Ruffin et al, 2005) and the role of public librarians as intermediaries in a health context has also been well documented (Linnan et al, 2004). In the UK, there have been recent specific initiatives which have examined the role of the public library in the context of online health information developments. These include a study which explored public access to web-based quality assured health information (Beard and de Vekey, 2004) and a separate study which looked at access to the National Electronic Library for Health (NeLH) in public libraries (McNicol and Nankivell, 2002). In an assessment of US-based projects around access to electronic health information, Ruffin et al (2005) highlight the theme of community engagement, which is of particular interest in the context of Informing Health: "Involving the target community in planning and designing activities increases each group's investment in the project" (Ruffin et al, 2005, p444). However, a 2006 report on UK public libraries and community engagement found that while some library services were working closely with their communities, many were not and that staff within the sector have fears about working in this way (MLA, 2006). The report goes on to make recommendations about how to build capacity and share good practice within the public library sector. Alongside the traditional provision of health information and the more recent move towards more inclusive working, public libraries are also expected to contribute to the wider health agenda of their local authorities. Supporting and promoting the health and well-being of communities is one of the key policy strands adopted by the Museums, Libraries and Archives Council (MLA):

Libraries specifically have an opportunity to interpret the role they can play as information providers in helping provide "informed choice for all" about health, mental health, healthy lifestyles, healthy eating, exercise and all public health priorities

(Weisen, 2004, 14)

One of the three main settings which the Choosing Health White Paper has established for supporting and promoting health is the local community, arguing that local communities and social networks can make a positive impact on personal health. It goes on to highlight the importance of strategic partnerships involving local communities: "We want to see an effective system for health 
delivered through close alignment between local community partners" (Department of Health, 2004, p197). Community-based health improvement programmes have been a key strand in UK government initiatives since the 1990s and, in Brighton \& Hove, the Healthy City initiative is built on community engagement and strong partnership: "Work with local people and partners across all sectors is improving the conditions that enable everyone to live healthier lives" (Brighton \& Hove City Council, 2006a, p21). Also in Brighton \& Hove, the neighbourhood regeneration project known as EB4U adopted health as one of its strategic themes along with an approach which emphasises community ownership and control. Indeed, the idea of partnership working is embedded in public health, and is likely to be the mainstay for health policy in the future, as noted by El Ansari and Weiss (2006).

\section{Use of the Internet for Health Information}

Successive surveys have shown the emergence of the internet as an important source for health information (Gunter, 2005). There is evidence from the United States that $79 \%$ nine percent of internet users have searched online for information on at least one major health topic (Fox, 2005) and while the accuracy of those figures can be contested there is no doubt that the internet is a valuable resource for many people looking for information on health. Existing research also suggests, however, that there is a close relationship between the so-called digital and health divides, with those groups most in need of support to improve and manage their health often finding it hardest to access and make effective use of information and ICT (Hughes et al, 2002). Many interventions that have been designed to address these inequalities have excluded from that design process the very groups they seek to support. This has resulted in the development of e-health initiatives and resources that do not match with users' needs and abilities and are therefore either not used or under-used. The Informing Health project sought to close this circle by involving users at the outset and enabling them to participate in the design process.

Participative approaches have been used effectively as both a tool for health promotion and for involving citizens in ICT policy development. Rifkin et al (2000) review the literature on participative tools in health promotion and include illustrative case studies of how tools have been employed. In the 1990s Sclove $(1995,1997 \mathrm{a}, 1997 \mathrm{~b})$ pioneered the use of participative tools as a way to involve citizens in debates about new technology and his work paved the way for the community informatics movement, whose goal is to enable communities to work effectively with ICTs. Closely related to the concept of participation is the principle of knowledge exchange, which recognises that knowledge flows are not uni-directional and that partners in a project all have knowledge to contribute. In line with these principles, the Informing Health project was conceived as a process of 'co-design', in which the users were central to the development of the initiative and the knowledge of all partners was valuable and a resource to be shared.

The main aim of the Informing Health project was to develop a model for good practice in community engagement around health information, with a focus on support for online health information seeking. It was designed to encourage 
partnership working with and amongst local library and information services and, crucially, to initiate more direct engagement with local communities. The partnership included local organisations involved in different aspects of health information provision along with local residents who were themselves involved with health improvement initiatives. The project adopted an approach based on participation and knowledge exchange, designed to encourage all partners to share knowledge and skills on an equal basis.

\section{Project objectives}

The key objectives of the project were:

- To form a partnership made up of some key providers and users of health information services in the city;

- To run a series of meetings where partners engage in a process of 'codesign' to develop ideas for library service interventions to support online health information seeking; and

- To pilot the design ideas through two workshops (one to be held in a public library, the other in the local NHS Hospital Trust library).

\section{The Partners}

Informing Health brought together partners with a range of knowledge and expertise in health promotion, online health information retrieval and healthy living interventions. The partnership included the local public library service, the NHS Trust library, the local health promotion team and a community-based healthy living initiative.

\section{Brighton \& Hove City Library Service}

In its strategy document, Libraries Forward (Brighton \& Hove City Council, 2006c) Brighton \& Hove City Library Service acknowledges the role of libraries in promoting healthier communities and the Head of Service was keen to be represented on the project. The public library service brought to the partnership an extensive knowledge of local public library services, the communities they serve and the City Council's priorities. They facilitated access to a community library for a workshop, where the partners had access to the computers at a time when the library was closed to the public.

\section{Brighton and Sussex University Hospitals Trust Library}

The NHS Trust library partner supports health in the community primarily by supporting health professionals. However, the library staff are also involved in several initiatives around patient information. These include the Carer and Patient Information Group (CPIG), which is looking at supporting the development of more and better patient information, and a pilot project designed to support the information needs of specific groups of patients and carers. The NHS Trust library brought to the project knowledge and experience of health information sources and a willingness to share this knowledge. Since 2005, the Trust library has housed the health promotion library. 


\section{Brighton \& Hove Primary Teaching Care Trust: Health Promotion}

The health promotion team work extensively in communities on neighbourhood renewal and healthy living initiatives. They are involved in initiatives such as the Brighton \& Hove Healthy City Partnership and produce resources for use by those working in health promotion and the general public e.g. the Active for Life website (Brighton \& Hove City Council, 2006b). The health promotion partner brought expertise in health promotion resources, an understanding of the nine neighbourhood renewal areas in Brighton \& Hove and a knowledge of community partnerships and facilities.

\section{Health4all Team at EB4U}

EB4U is the organisation responsible for the management and delivery of the New Deal for Communities regeneration programme covering several communities in East Brighton. The Health4all team acts as a focus for health issues in EB4U and team members co-ordinate local health-related initiatives, promote health in an innovative way and provide an information resource for local people and service providers.

Informing Health involved a member of the Health4all team, the Fresh Ideas Worker, as well as community participants who were already actively engaged in some of the health initiatives. The role of the Fresh Ideas Worker within Health4all is to give support and development advice to resident groups, schools and businesses in setting up community-based food initiatives, particularly around increasing access to fresh fruit and vegetables. The Fresh Ideas Worker was key to the Informing Health project. She acted as a gateway into the communities and facilitated access to community groups such as the local food co-ops and weight management groups.

The community residents who agreed to participate were involved in several of the community health initiatives, including:

- The Food Interest Group - a semi-formal group including residents, voluntary groups and statutory service which meets on a regular basis to talk about food and health and organise activities;

- Bulge Beaters - an informal community based weight management group;

- Food Co-ops - volunteer-run initiatives to buy and sell fruit and vegetables at cost price;

- Babies Early Support Team (BEST) - a group for young mothers which met in a local community centre and focused on breast feeding.

The community participants brought with them a knowledge of their own communities along with experience of health-related community initiatives, as volunteer workers, users or both. They were all familiar with different health issues and conditions and - to varying degrees - with looking for health information in different ways. 


\section{The process}

The process was essentially a series of meetings and workshops which took place over the six-month period of the project. The content of the workshops was deliberately left as open as possible but it was envisaged that there would be some sort of training element related to online health information seeking.

Preparation and groundwork were important for 'buy-in' and the first stage was a series of bi-lateral meetings with each potential partner in order to explore the issues and confirm participation. Meetings were held in the partners' places of work and, in the case of the community participants, in centres of activity within the community. The second stage was a series of all-partner events. Three such events were planned at the outset: an introductory meeting and two hands-on workshops. It was hoped that the workshops would reach the stage of trialling methods designed to improve access to online resources. The first all-partner meeting and the first workshop worked well. Unfortunately, the second workshop had to be abandoned at the last minute because the community partners were unable to attend, which obviously had serious implications for the outcome of the project.

\subsection{All-Partner Meeting}

The first all-partner meeting was held at a local leisure centre and it had three objectives: to provide an opportunity for the partners to get to know one another; to initiate a discussion of the key themes; to start to explore whether a partnership project of this nature was possible. The discussion was key to the whole project, since it was the main opportunity to explore the perspectives of the partners and to start to identify where and how assumptions were shared or differed. An icebreaker was used to encourage participants to talk to someone they did not already know and to introduce each other to the group. The key themes were then outlined by the university partner:

- The importance of positive approaches to health e.g. the Health4All initiative;

- The role of information;

- Access to information in communities where people live and work;

- The role of the internet;

- The role of libraries;

- Learning from each other.

The group then split into two - community participants and service partners - to discuss the themes and then the whole group reconvened. Several key issues arose from the session.

\subsubsection{Health}

Health was understood differently by the different partners. For the service providers in health, it is their bread and butter, although the focus for the NHS Trust library is the service they provide for healthcare professionals employed by 
the local Trusts. The Health Promotion partner, in contrast, works at community and strategic level, with a focus on healthy living and community development. The public library service partner has a general remit, but giving access to health information for the public is important. The community participants expressed views about health in different ways. For the young mother, children's health including food and diet - was important. The other community participants talked about health in terms of problems with local health services, for example, catering and parking problems at the local hospital.

\subsubsection{Health information}

The public library gives access to a wide range of health information sources, paper-based and online, but it did not offer specific training on finding health information to either its own staff or the public. The NHS Trust library offers a 24/7 service for their core users - health care professionals - as well as training courses on finding health information and assessing information quality on the internet. The training courses have been piloted with groups of patients and carers, for example, on renal health. The health promotion library service advises health promotion staff about health information websites, preparing lists of 'vetted' sites. The service itself produces and promotes websites on healthy living.

For the community participants, the predominant ways to access health information were from other people: word of mouth and in community groups, with leaflets and newsletters also seen as useful. The young mother said she preferred to receive information related to childcare from groups rather than go to the library because she enjoyed the contact with other group members. She also commented that not everyone has access to computers. Another community participant said that although she had a computer she did not have the skills to use it. Yet another community participant, however, spoke about using the internet to look up recipes to share with the Bulge Beaters group.

\subsubsection{Libraries}

The young mother said that she would like more mobile library services as the local community library was too far away. The community participants agreed that library opening hours were problematic e.g. lunch-time closing; not fitting with local playgroup times. Another community participant felt that school libraries could offer courses to parents and the local community. Other community participants aired grievances about the libraries, which ranged from opening hours and locations to uneven paths and a lack of newspaper provision. While it was pointed out that the public library has computers which are free for public use it was felt that there were too few of them and there was very little training or support available.

One of the community participants suggested that libraries should publicise themselves and their services more in the community. The health promotion partner suggested that the key issue is how to bring information to the community and that community centres are a possible alternative to libraries for offering access to information and training. Some local community centres have wireless 
access to the Internet and are generally more accessible to community members than libraries.

It was suggested that the public library, hospital library and health promotion services could work together better to provide links to health information websites. There was also a suggestion that community networks be used to distribute information on courses relating to health information and ICT training.

The next stage of the project was discussed and while some of the community participants were concerned that they were "workshopped out" all partners agreed to come to a workshop in one of the local public libraries, where they would be given the opportunity to explore online health information resources and discuss the experience. They agreed to come prepared with a health-related enquiry.

\subsection{Public library workshop}

The workshop took place in a community library, the local library for several of the community participants, on a day when it was closed to the public. The workshop began with a resumé of the first meeting, noting some of the key discussion points.

The group then worked in self-selected pairs at the library computers, looking at health information sites. They were given a leaflet produced by the Trust library: Finding reliable health information online and it was suggested that they start with some of the sites on the leaflet. They worked at the computers for about an hour, with the university partner on hand for advice. The pairing-up worked well and those who were used to using computers helped those who were less confident. Two of the community participants had no experience of using the Internet but they began to navigate their way around fairly quickly. One of the university partners worked with the public library partner, both used to Internet searching. As well as looking for information they also assessed the sites they accessed and the leaflet provided by the Trust library.

At the feedback session, all three community participants spoke about the potential the Internet offers for access to information and for widening horizons. Typical comments from the community participants were:

Very interesting

Once you get into it you do open up a whole new world You can find out a lot more than reading in ordinary books

They spoke about the information they found, which tended to be about health conditions or treatments and on subjects they were personally familiar with. They also talked about the language used on sites, in particular the medical jargon and some of the physical aspects of Internet searching: "It wears your eyes out after a while". It proved more problematic, however, to get the participants to think about the underlying processes involved in using the Internet to look for information and how they might translate what they had been doing into workshops which they themselves might facilitate or host. The next stage was therefore envisaged by the university partner as a means to try to tease more of this out using a 2-step process: 1) to look up sites, including local sites, and reflect on the content and 
searching processes and 2) to encourage all the partners to think about how they might design some training to fit their needs. As a step towards this, the community participants agreed to bring along a friend each to a second workshop, to be hosted in the NHS Trust Library. The Trust partner agreed to invite the member of staff involved in training patients and carers in online health information to attend.

Unfortunately this second workshop did not take place as planned. The community participants were unable to attend for a variety of logistical and personal reasons. Their non-attendance at the workshop obviously impacted on the project in a practical way, which will be discussed later. The more general implications for participation and partnership working will also be explored.

\section{Evaluation}

The project was formally evaluated through completion of an evaluation form and follow-up meetings.

There was general agreement amongst the service partners that the project had gone some way to establishing an effective partnership, albeit on a small scale, and that the partnership working had enabled some tangible benefits. The knowledge exchange aspect of the process, particularly the discussions at the first all-partner meeting, helped to underpin the partnership although, as will be noted in the discussion section, equitable knowledge exchange is not easy to put into practice. Specific outcomes were noted by the partners. For example, the comment from the community resident about how public libraries needed to promote themselves more in the community was followed up by the public library partner. The health promotion partner offered access to community centres for public library promotional material, which was taken up by the public library partner. A further practical outcome was that staff in the Hospital Trust library have begun to work with their public library colleagues to plan and run training courses in online health information skills for public library staff.

The public library partner stated that they had gained a better understanding of the information the local NHS Trust library can provide and the training opportunities the staff there offer. They also gained further understanding of community needs - not only in relation to health information but also with regards to general library provision.

The Fresh Ideas Worker from Health4all at EB4U reported that the project had opened her eyes to library and information services and provided an opportunity for other service providers to understand her work. She felt that the project had helped build capacity in the communities she works with.

The community residents reported that they had gained new skills in using computers and searching for health information.

Looking for information was good. I have a nursing background so I understood a lot. Someone has offered to build me a computer.

The community participant who was the experienced computer user showed patience and skill in teaching one of the others. This example prompted the 
public library service to entertain the possibility of using community volunteers as ICT trainers in community libraries.

In general, the benefits were summarised:

- An increased understanding of how each of the partners worked;

- An increased understanding of where perceptions and assumptions were shared and where they differed;

- Ways of working more closely together identified.

\section{Discussion}

This discussion relates the findings from this project to the themes outlined in the introduction.

\subsection{Health and health information}

Health was understood differently by the different partners. The focus of the project was explicitly on health in the sense of well-being and was the rationale for involving partners in healthy living initiatives. However, in both the discussion sessions and the workshop, the older community participants tended to interpret health in terms of health conditions and local service provision and they reflected this in the way they approached the online information session at the library workshop. This corresponds with findings from a 2003 survey, which found that the most common reason for visiting the Medline Plus ${ }^{2}$ website was to find information on a specific condition (Ruffin et al, 2005, p435).

It indicates perhaps the need for a more prominent approach to information and communication related to health and well-being. One potential way forward is to build on the type of partnership brought together by Informing Health and to adapt other existing initiatives. For example, the NHS Expert Patients Programme ${ }^{3}$ offers support to people with long-term medical conditions and gives them the opportunity to attend local courses and workshops. Workshops include sessions to develop online information skills around specific illnesses and conditions. They could be adapted to focus on healthy living information.

\subsection{The role of libraries}

It is recognised in government policy documents that public libraries have an important role to play in their communities. As the MLA report on public libraries and community engagement points out "libraries are located in communities and are often the only council presence in an area. They offer opportunities to support wide social policy agendas and to use their vantage point as a community resource" (MLA, 2006). Brighton \& Hove's library strategy echoes this in a visionary aim to "enrich people's lives by providing a focus for community interaction, communication and engagement..." (Brighton \& Hove

\footnotetext{
${ }^{2}$ Medline Plus is a leading web-based source of health information. http://medlineplus.gov

${ }^{3}$ The NHS Expert Patients Programme is a national initiative, with workshops and events also organised on a local basis: http://www.expertpatients.nhs.uk
} 
City Council, 2006c, p2). As the MLA study reveals, community engagement is something which public libraries are doing less effectively than they might and Informing Health indicated that many local residents do not regard libraries as an obvious focus for community activity. At the early bi-lateral meetings in the community centres, few of the people we spoke to ever went to their local library or considered the library as somewhere to go for information. As a result of the project one participant, initially sceptical, had become an enthusiastic library user, borrowing and requesting books:

I go to the library regularly now. I've got out a book on computers and one on Nelson Mandela and two cookery books.

However, she said that she would be unlikely to use it to access the computers:

They [the users] all look so intense; all hunched over. And there isn't any help like on the computer course when you can shout 'help' over your shoulder to [the instructor]. It's intimidating because I'm such a learner. Maybe there should be cubicles where you could hide away...

Her statement is illuminating in that, as well as portraying a rather negative image of the typical library computer user, she also highlights issues around lack of confidence and the need for support. Using the internet as such did not prove to be problematic for the community participants in the library workshop but they needed a considerable amount of guidance, encouragement and support.

As was outlined in the introduction, public libraries feature prominently in current government policy as places where access to online information will be provided and supported. However, it was not the obvious first port of call for our community participants and limited resources impact on the levels of support the service is able to offer.

\subsection{Partnership and knowledge exchange}

As was noted in the evaluation section, there were positive outcomes created by the partnership working in Informing Health. However, even although the project was small in scale it experienced some of the problems associated with partnership working. The involvement of community partners tends to add further layers of complexity, as outlined by Mayo and Taylor (2001), much of it related to power imbalances. The university partner was the power broker in Informing Health. It was the lead partner and set the agenda and while this was made explicit from the beginning it nevertheless meant that the partnership was not equal in terms of power.

At the leisure centre meeting, the division of the partners into community participants as one discussion group and service providers as the other, was done deliberately to even out the power balance. As Coulson (2005) notes, community participants can be put into impossible situations because they "have little real power" and "do not find it easy to challenge professionals with many years training and experience". It was felt by the university partner that the community participants would contribute more easily as a group with someone they knew and trusted as the facilitator, in this case the Fresh Ideas Worker. The group split was successful to the extent that it generated a wealth of ideas and discussion. 
However, one community participant was uncomfortable about it and did not continue with the project after the first meeting. She has been involved in many local strategic partnerships and may have felt that the split was unnecessary or unwelcome, mirroring as it did a user-provider divide. In her case, the attempt to even out the power may have backfired.

The literature on health information outreach programmes highlights the importance of developing relationships at the outset with "key community contacts" (Burroughs, 2004, p66). The individuals who volunteered for Informing Health were active in their communities and in projects such as the food co-ops, which have a collective benefit. The expectation from the university partner therefore was that those community participants would speak to that collective goal. However, the participants themselves tended to assume that they were participating as individuals. They were positive about the personal benefits they had gained from the project and could identify other individuals who they thought would also benefit, but there was little sense of how, at the food co-op, for example, they might contribute knowledge about health and well-being or how they might use libraries or online resources to support their work. In contrast, the service providers tended to speak in a collective way, representing their organisation's rather than their individual interests. Those service provider partners who were involved in community development work likewise referred to the communities in which they worked in a collective way. This situation led to a mis-match of expectations within the partnership and led to some partners questioning if the project had the "right people". In apparent contradiction, the onus for maintaining involvement with the project within the service provider partner organisations was very much left to the individuals who had been nominated by their managers. Likewise, the initiatives which were taken forward as a result of the project - such as the promotion of community library services in other community centres - were as much a result of individual drive as organisational impetus. The issue raises questions about the selection of participants in a project of this nature and the need to challenge the roles and assumptions around individual and collective participation.

The emphasis of the project was on participation through knowledge exchange. The project used facilitated discussion and participatory workshop techniques to encourage the partners to engage in a process of 'co-design' to develop ideas for library service interventions. The leisure centre meeting was successful in that all partners brought ideas to the table and shared in general discussion. The library workshop was also successful in encouraging partners to share knowledge, skills and experience. However, the progression towards 'co-design' proved to be trickier. This was partly due to lack of time and also to the issues around individual and collective participation already discussed. More interestingly, perhaps, the evaluation process showed that while the 'service provider' partners were clear about what they had brought to the project the community participants were reluctant to recognise that they had contributed anything at all. "I know what I learned...but what we brought?" was a typical puzzled response. The community participant who had helped his colleague to navigate internet sites to find relevant health information only acknowledged his achievement after some prompting and then only modestly: "Oh, yes, well it's good to know you can help 
people". He remained bemused by the experience: "What was the thinking behind this then? Was it to get us to read more books?" His questions illustrate some of the difficulties inherent in moving away from the traditional top-down model towards a more equitable exchange of knowledge, as well as the problems for public libraries of moving away from the traditional book-focused image. The project attempted to encourage community representatives to articulate their own skills and experiences and think of themselves as contributors to as well as recipients of knowledge and training. The model proved to be elusive. This, along with the time limitations of the project, meant that less progress was made than had been anticipated on developing a model of good practice for engaging the community in online health seeking. However, there were indications about how such a model could be initiated:

- Involving those already engaged in 'healthy living' initiatives in the local community in library service developments aimed at 'the public';

- Involving community groups in the assessment and evaluation of online resources before finalising recommended list of websites etc.;

- Developing mechanisms to help community representatives articulate their own skills and experience ;

- Encouraging community representatives to think of themselves as contributors to as well as recipients of knowledge and training;

- Using community residents' expertise to train and support others.

\section{Conclusion}

The project set out to build a partnership of key stakeholders in health information and to pilot participative approaches to improved access to online health information in the community. The project demonstrated some positive aspects of partnership working and community engagement, which can be used as a basis for further development and research work. It equally illustrated some of the difficulties inherent in partner relationships and the challenges of knowledge exchange. 


\section{References}

Beard, J., de Vekey, J and Ball, D. (2004) The quality of assurance of Healthinfo4u: a web-based internet resource for the lay public, Performance Measurement and Metrics 5(1), 28-34.

Brighton \& Hove City Council (2006a) Creating the city of opportunities: a sustainable community strategy for the City of Brighton \& Hove. URL: http://www.2020community.org/files/communityStrategy.pdf

Brighton \& Hove City Council. (2006b) Active for life: more people, more active, more often. URL: http://www.activeforlife.org.uk.

Brighton \& Hove City Council (2006c) Libraries forward strategy. URL: http://www.citylibraries.info/information/documents/forward_strategy_06.doc

Burroughs, C. M. (2004) Evaluation in health information outreach programs. Reference Services Review, 32 (1), 64-68.

Coulson, A. (2005) A plague on all your partnerships: theory and practice in regeneration, International Journal of Public Sector Management, 18 (2), 151163.

Department of Health (2004) Choosing health: making healthy choices easier. London: Department of Health.

El Ansari, W. and Weiss, E.S. (2006) Quality of research on community partnerships: developing the evidence base. Health Education Research, 21(2), 175-180.

Fox, S. (2005) Health information online. Pew Internet Project. URL: http://www.pewinternet.org/pdfs/PIP_Healthtopics_May05.pdf

Gunter, B. (2005) Online health services - who uses what? Update, 4 (5), 42-43

Hughes, K., Bellis, M. A \& Tocque, K. (2002) Public health and Information \& Communication Technologies: tackling health and digital inequalities. Liverpool: John Moores University

Linnan, L.A., Wildemuth, B.N., Gollop, C., Hull, P., Silbajoris, C., Monnig, R. (2004). Public librarians as a resource for promoting health: results from the health for everyone in libraries (HELP) librarian survey. Health Promotion Practice, 5 (2), 182-190

Mayo, M. and Taylor, M. (2001). Partnerships and power in community regeneration. in Balloch, S. and Taylor, M. (eds) Partnership working: policy and practice. Bristol: The Policy Press.

McNicol, S and Nankivell, C. (2002). Creating access to the National electronic Library for Health. London: ResourceURL:

http://www.ebase.uce.ac.uk/cirtarchive/publications/NELH.pdf

MLA (2006). Community engagement in public libraries: a report on current practice and future developments. London: MLA. URL:

http://www.mla.gov.uk/resources/assets//C/community_engagement_report_9654. pdf 
Rifkin, S. (2000) Participatory approaches in health promotion and health planning: a literature review. London: Health Development Agency

Ruffin, A. B., Cogdill, K., Kutty, L. \& Hudson-Ochillo, M. (2005). Access to electronic health information for the public: analysis of fifty-three funded projects. Consumer Health Issues, Trends, and Research: Part 2. Applicable Research in the 21st Century, 53(3), 434-52.

Sclove, R. E. (1995) Democracy and technology. New York: Guilford Press.

Sclove, R. E. (1997a) Historic, first-time U.S. Citizens' Panel. Loka Alerts 4(2).URL: http://www.loka.org/alerts/alerts.htm

Sclove, R. E. (1997b). Telecommunications and the future of democracy. Loka Alerts 4(3). URL: http://www.loka.org/alerts/alerts.htm

Weisen, M., (2004) New directions in social policy: health policy for museums, libraries and archives. London: MLA. 